\title{
LEADERSHIP SKILLS IN DENTAL CURRICULUM- A REVIEW
}

\author{
Othman Wali ${ }^{1}$
}

${ }_{1}^{1 B D S}$, MSc., Swedish Board, Perio-Prosth Fellowship from University of Florida, USA. Vice Dean of Dental Program, Ibn Sina National Medical College, Jeddah, Saudi Arabia.

\begin{abstract}
BACKGROUND
Dental profession is shaped by several forces in an ever-changing environment. Current focus on technical skills alone cannot prepare the student for a career in research, practice or other administrative positions. Leadership skills introduced in the undergraduate curriculum represents the best opportunity to train students to be future leaders. This review focuses on the need and competencies that are required to implement leadership development program in undergraduate curriculum.
\end{abstract}

ABSTRACT

\section{KEY WORDS}

Leadership, Dentistry, Dental Education.

HOW TO CITE THIS ARTICLE: Wali O. Leadership skills in dental curriculum- a review. J. Evolution Med. Dent. Sci. 2018;7(42): 4584-4588, DOI: $10.14260 /$ jemds/2018/1022

\section{BACKGROUND}

Relationships amongst healthcare professionals, allied service providers and patients are dynamic and in a constant state of flux. Several external forces continue to shape the dental profession including changing demands and therapeutic options, commercialisation of dental services and products and tremendous increase in the access to information in the public domain.(1) Other challenges include the need for sensitivity to cultural practices, patient safety, functioning efficiently in a team framework and address disparities in oral health.(2) Dentists are required to manage efficient small businesses and complex staffing issues, concomitantly planning for an uncertain future.(3) Thus, a new graduate is thrust into an ever-changing environment with a necessity to constantly adapt.

A dental student may eventually end up choosing to extend services into various fields including: private solo or group practice, government or private administrative positions in education, public health, research or community service. Each field presents its own set of problems. Dental education faces serious challenges in the form of escalating costs and corresponding student debt, faculty shortage and curricula that have often failed to keep abreast with the current environment.(4) Epidemiological data has also highlighted targeted deficiencies in provision of oral health care for disadvantaged populations such as minority children, the elderly and individuals with special health care needs.(5) While a large population of dentists are solo practitioners, a perceptible change towards group practices can be noticed and there is a need for dentists to develop hitherto neglected skills such as robust leadership, negotiation and collaborative skills.(6) Clinicians are primarily trained in clinical expertise, but are eventually required to assume management responsibilities. Thus, sophisticated leadership skills, attitudes and abilities are necessary to navigate the clinician manager role successfully. ${ }^{(7)}$

'Financial or Other Competing Interest': None.

Submission 30-08-2018, Peer Review 28-09-2018,

Acceptance 03-10-2018, Published 15-10-2018.

Corresponding Author:

Othman Wali,

Vice Dean of Dentistry Program,

Ibn Sina National Medical College, Jeddah-22421, Saudi Arabia.

E-mail: owali@ibnsina.edu.sa

DOI: $10.14260 /$ jemds/2018/1022

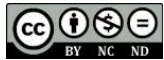

In the context of the several roles being asked of the dental student to play and in the face of the significant challenges being faced by the dental profession, proactive leadership seems to be lacking.(8) Within this environment, dentists may be exposed to undue stress on account of the fact that leadership attributes and skills required to successfully negotiate these circumstances may be missing or inadequate. Leadership skills are not necessarily inherent to dentists and formal training in leadership is the need of the hour.(6) Arguably, leadership is a complex and difficult skill to develop ${ }^{(9)}$ and paradoxically leadership in dentistry remains one of the most neglected in comparison to the other clinical professions(10) with very little research conducted on the impact of leadership in dentistry.(11) It is imperative that dental professionals participate in the process of redesigning their future plans to arrive at a new vision and mission that includes an expanded role to embrace the entire dental team. ${ }^{(8)}$

One of the important measures to enhance the capability of dental health care professionals to address current and future changes is to educate them to be future leaders.(12) An effective dental leader ensures employee satisfaction, provides opportunities to be role models and agents of change within their local communities.(12) Leadership development at earlier career stages, is the optimal way for "early identification and purposeful development of leadership talent, interest and abilities."(13) Studies demonstrate that both faculty/ administrators and students appreciate the value of and need for student leadership development.(14)

\section{What is Leadership?}

The viewpoint of what leadership means is an area of considerable debate. Leadership has been considered an activity, not a position and may even be fleeting in-themoment interventions. Thus, leadership in dental education means mobilising others to make progress on difficult issues.(15) "Leadership entails the effective communication of a vision (whether shared or not) and an honest and in-depth evaluation of collective experiences and/ or available data so that organizational change may occur in a rational manner".(16) A collaborative, shared leadership style,(10) with core concepts including " leadership as a trait, leadership as an ability, leadership as a skill, leadership as a behaviour and leadership as a relationship" has been advocated as a suitable 
definition of leadership in dentistry.(17,10) Though frequently clubbed together, differences between leadership and management exist which need to be noted. The essential difference is that leadership means leading by example, whereas management is focused on implementation in the best possible way.(18)

\section{How to go about Developing Leadership Skills}

The role of a dental school and the traditional curriculum in the context of leadership, mostly refers to the development of technical and scientific skills. However, formal leadership training programs that focus on helping students learn how to successfully build a team, communicate effectively and enhance decision making skills(12) must be considered as a critical mandatory learning opportunity. Moreover, the program must entail universal student participation rather than a select few, since a potentially diverse range of situations may see the emergence of leaders from least expected sources.(19) A general set of attributes are thought to be necessary for the development of leadership skills (Table No. 1). The leadership development program may do well to enhance personal and organisational learning opportunities taking into consideration the leadership style of the individual.(20)

Personality/ traits, behavioural style, situational/ contingency and transformational leadership are some of the well-known theoretical approaches to leadership(10) However, there is no consensus on the most appropriate leadership theory or approach, either in general terms or specifically in relation to dental surgeons. Nevertheless, a practical and more popular mode is the competency approach in dental education. ${ }^{(10)}$

\section{Competencies for Leadership}

Leadership competence in a clinical or research setting can focus initially on the knowledge and concepts of leadership. A set of competencies, not exclusive to dentistry have been deemed essential to achieve leadership skills.

\section{Team Building: Communication and Conflict Management}

The importance of communication skill development as a cornerstone for leadership cannot be understated. In clinical practice, research or community service, aspects such as motivating stakeholders, networking, negotiations, conveying point of view and disseminating information, competence in communication skill (both verbal and non-verbal) may be the differentiating factor between success and failure.(12) Indeed, student's perception reflects that they desired 'more' on communication skills in spite of having been administered a module on communication.(21) Communication exercises designed to mimic difficult real life situations and a framework to deal with them can help students enhance their communication skills. (22)

Dentistry as a profession has a responsibility to address not only the problems of normal/ privileged populations, but also cater to the needs of underserved communities and populations. The communities as well as the students' learning dentistry come from diverse cultural backgrounds. Effective team building requires at least in part cultural awareness while providing patient care, working together as part of the oral health care providers team or during interprofessional interactions. Ability to trust and conflict management are additional components of team building that can be taught preferably by discussions and team projects. Conflict management ability is developed individually by evaluating the five conflict-handling modes or stylescompeting, collaborating, compromising, avoiding and accommodating.(23) Rather than a "one glove fits all" approach, discussing the most suitable style for a given situation is a better strategy. Overall, formal teamwork training has been shown to be effective in improving team behaviours, reducing errors and improving staff attitudes.(24)

\section{Ability for Self-Reflection/ Self-Awareness}

Self-reflection is one of the essential qualities of a great leader, since it promotes the trait of being true to oneself.(12) A thorough understanding of one's own approach enhances self-awareness and empathy by highlighting the differences that are inherent to team functioning.(22) Indeed, colleagues and staff who believe their leader to be self-aware are more likely to support him/ her, especially during difficult times.

\section{Critical Thinking and Problem-Solving Skills}

Critical thinking is regarded as "intellectually engaged, skilful and responsible thinking that facilitates good judgement because it requires the application of assumptions, knowledge, competence and the ability to challenge one's own thinking."(25) Critical thinking can catapult a good leader to a great one, since experience of resolving issues alone may not be sufficient in a world of constant change. Though researchers debate if critical thinking can be learned, instructional strategies can influence what is learned.(25)

Critical thinking can be taught by simulation-driven learning experiences, frequent use of questions by instructors that require students to analyse problems, listening to the reasoning of expert practitioners, comparing experiences to that of expert practitioners(25) and writing assignments that request students to analyse problems. (26)

An appropriate environment that provides students both time and space to reflect and think critically is required to develop critical appraisal skills. Fostering the ability to ask many questions, focusing on topics or situations that evoke an energetic response and present and apply existing concepts in innovative ways are habits that over time can enhance the critical thinking process.(12) Critical thinking is essential to address not only challenges or emergencies, but also in day-to-day activities.

\section{Ethics}

Ethical leadership is imperative and indispensable; nevertheless, knowledge alone will not prepare students for the potentially complex situations they may face in their routine professional life. Case studies with thorough discussions on the ethical principles applied along with acceptable alternatives are needed to grasp student's attention. Interplay between legal aspects and ethics are needed to comprehensively prepare students with an armamentarium to deal with real life situations. Academic institutions and the various stakeholders such as faculty and administrative staff are also required to set an example of ethical behaviour to be emulated by students in their future professional endeavours.

\section{Professionalism}

Professionalism may be defined as "a life characterised by display of high intellectual, technical and moral qualities and 
abilities in service to patients and community."(27) Professionalism is and must be an integral part of student education and lifelong learning. Nevertheless, most professional attributes in dental education are acquired as a by-product of completing the curricular requirements and not by focused dedicated instruction.(28) Additionally, reports of unprofessional behaviour by dentists, broad changes in society and modified policies of regulatory bodies has led to an increased educational interest for the concept of professionalism which in turn has led to a greater focus on ways of implementing and assessing professionalism in dental, medical and other professional courses.

\section{Assessing Leadership Competence}

The leadership skills may be taught as a set of modules or as a separate leadership development program. Either approaches may then ultimately be reflected in terms of

\begin{tabular}{|c|c|c|}
\hline Compassion & Positive mental attitude & Integrity \\
\hline Advocacy skills & Faith & Being good at problem \\
\hline Inquiry skills & Goals in life & solving and building \\
\hline Empathy & Organisation & relationships \\
\hline Ability to influence & Time management & The ability to communicate \\
\hline Self-management & Interdependency and synergy & Clearly, \\
\hline Relationship management & Consistency & Earning respect from the \\
\hline Authenticity (transparency) & Communication & dental team \\
\hline Integrity & Self-renewal & Being good at motivating \\
\hline Ability to build trust with others & Empathy and humility & Peers (28) \\
\hline Personal responsibility & Creativity & \\
\hline Managing conflict & Personal responsibility and drive & \\
\hline Leading groups/ teams & Ability to say no & \\
\hline Dealing with difficult & Charisma. (27) & \\
\hline personalities & & \\
\hline Likelihood to exercise & & \\
\hline leadership during a crisis (2) & & \\
\hline
\end{tabular}

Manage and maintain a safe working environment.

Effectively integrate other members of the dental team with regard to risk management.

Effectively raise concerns in an appropriate manner at various levels. Manage adverse events in the short and longer term.

Consider implementing changes within the team and the wider practice environment that will significantly improve efficiency and sustainability of resources. (31)

Demonstrates effective leadership within the healthcare team where appropriate, including the support of all team members.

Takes account of quality assurance, quality improvement and patient safety, and develops, implements and evaluates strategies to improve quality.

Understands the principles of adult learning and facilitates the learning of patients, families, carers, colleagues and the public as appropriate.

Understands the value of mentoring and being a positive role model for other members of the healthcare team.

Understands how to act in the interests of patients who have been subjected to clinical harm or errors and how to obtain 
appropriate advice and support.

The foundation dentist can demonstrate to an appropriate standard the ability to:

Select, implement and evaluate strategies to facilitate effective learning.

Accept and provide effective feedback in a manner that motivates and encourages learning.

Present effectively to colleagues ensuring understanding and meeting the expectations of the audience.

Demonstrate clinical skills and competencies to other colleagues in an effective manner. (32)

Table 2. Competencies for Dental Leadership (Clinical) and Management(31,32)

\section{CONCLUSION}

Dental profession needs to treat every single graduating and graduated dentist as a potential leader. These skills are essential in a scenario, where the very basis of terming dentistry as a profession is being questioned with calls to brand it a business. Technical skills development is being focused on, but leadership training is sadly lagging behind. Dental schools and curricula represent the best opportunity to start training a future generation of dentists who will be well equipped to deal with these dynamic challenges, even as leadership programs for graduated dentists is on the rise. It would be an inspiring beginning if at least the authorities associated with regulating dental professions in different countries initiate a discussion at the very least, on the means of implementing leadership development programs in dental schools.

\section{REFERENCES}

[1] Taichman RS, Parkinson JW, Nelson BA, et al. Leadership training for oral health professionals: a call to action. J Dent Educ 2010;76(2):185-91.

[2] Kalenderian E, Skoulas A, Timothé $P$, et al. Integrating leadership into a practice management curriculum for dental students. J Dent Educ 2010;74(5):464-71.

[3] Taichman LS, Taichman RS, Inglehart MR. Dentists' leadership-related educational experiences, attitudes, and past and current behavior. J Dent Educ 2014;78(6):876-85.

[4] Roth K. Dental education: a leadership challenge for dental educators and practitioners. J Dent Educ 2007;71(8):983-7.

[5] Mouradian WE, Huebner C, DePaola D. Addressing health disparities through dental-medical collaborations, Part III: Leadership for the public good. J Dent Educ 2004;68(5):505-12.

[6] Nalliah RP. Do dentists make poor leaders? Br Dent J 2016;220(8):389-91.

[7] Forbes T, Hallier J, Kelly L. Doctors as managers: investors and reluctants in a dual role. Health Serv Manage Res 2004;17(3):167-76.

[8] Morison S, McMullan C. Preparing for the future: challenges and opportunities for management and leadership skills. Br Dent J 2013;214(1):E2.

[9] Levin R. The dentist as a leader. J Am Dent Assoc 2003;134(10):1391-2.

[10] Willcocks S. Leadership theory: implications for developing dental surgeons in primary care? Br Dent J 2011;210(3):105-7.
[11] Walsh J, Taylor N, Hough D, et al. A qualitative evaluation of a pilot leadership programme for dentists. Leadership in Health Services 2015;28(3):185-99.

[12] Taichman RS, Parkinson JW, Nelson BA, et al. Program design considerations for leadership training for dental and dental hygiene students. J Dent Educ 2012;76(2):192-9.

[13] Victoroff KZ, Schneider K, Perry C. Tomorrow's leaders, starting today: a pilot leadership development program for dental students. J Dent Educ 2009;73(3):311-8.

[14] Hammer DA, Nadershahi NA. Assessing the demand and preferred format of a student leadership development program at Pacific. J Dent Educ 2011;75(8):1044-52.

[15] Cohen PA, Tedesco LA. Willing, ready, and able? How we must exercise leadership for needed change in dental education. J Dent Educ 2009;73(1):3-11.

[16] Taichman RS, Green TG, Polverini PJ. Creation of a scholars program in dental leadership (SPDL) for dental and dental hygiene students. J Dent Educ 2009;73(10):1139-43.

[17] Northouse PG. Introduction to leadership: concepts and practice. London: SAGE 2009.

[18] Imboden S. Effective leadership. In: Motarjemi Y, Lelieveld $\mathrm{H}$, eds. Food safety management: a practical guide for the food industry. 1st edn. Academic Press 2014:959-73.

[19] Victoroff KZ, Schneider K, Perry C. Leadership development for dental students: what do students think? J Dent Educ 2008;72(9):982-8.

[20] Slavkin HC, Lawrence L. Incorporating leadership knowledge and skills into the dental education community. J Dent Educ 2007;71(6):708-12.

[21] Kalenderian E, Taichman RS, Skoulas A, et al. Developing the next generation of leaders in oral health. J Dent Educ 2013;77(11):1508-14.

[22] Skoulas A, Kalenderian E. Leadership training for postdoctoral dental students. J Dent Educ 2012;76(9):1156-66.

[23] Kilmann RH, Thomas KW. Developing a forced-choice measure of conflict-handling behavior: the "Mode" instrument. Educ Psychol Measures 1977;37(2):30925.

[24] Morey JC, Simon R, Jay GD, et al. Error reduction and performance improvement in the emergency department through formal teamwork training: evaluation results of the Med Teams project. Health Serv Res 2002;37(6):1553-81. 
[25] ADEA: Overview of critical thinking skills. https://www.adea.org/adeacci/Resources/CriticalThinking-Skills-Toolkit/Pages/Overview-of-CriticalThinking-Skills.aspx

[26] Hendricson WD, Andrieu SC, Chadwick DG, et al. Educational strategies associated with development of problem-solving, critical thinking and self-directed learning. J Dent Educ 2006;70(9):925-36.

[27] Masella RS. Renewing professionalism in dental education: overcoming the market environment. J Dent Educ 2007;71(2):205-16.

[28] Stern DT. Measuring medical professionalism. New York: Oxford University Press 2006.

[29] Tricio J, Woolford M, Escudier M. A survey of dental schools' assessment strategies. European Journal of Dental 2015. http://www.tricio-education. com/dinamicos/descargas/presentacion-adee-agosto2014-riga-latvia.pdf
[30] Christensen GJ. Fourteen characteristics of effective leaders in dentistry. J Am Coll Dent 2004;71(4):18-21.

[31] Hill H, Brocklehurst P. Leadership in dentistry: findings from new tool to measure clinical leadership. J Healthc Leadersh 2015;7:13-20.

[32] Field JC, DeLap, Manzanares Cespedes MC. The graduating European dentist-domain II: safe and effective clinical practice. Eur J Dent Educ 2017;21 Suppl 1:14-7.

[33] Committee of Postgraduate Dental Deans and Directors (COPDEND) UK. Dental Foundation Training Curriculum 2015. http://www.mjdf.org.uk/wpcontent/uploads/2017/07/DFT-final-version-v6-

31.pdf 